\title{
The EPA P3 Program: an Opportunity for Growing Student Entrepreneurs
}

\section{Dr. Yan Tang, American Society of Mechanical Engineers}

Dr. Yan Tang is an assistant professor of Mechanical Engineering at Embry-Riddle Aeronautical University in Daytona Beach, Fla. Her current research in engineering education focuses on cognitive load theory, deliberate practice and effective pedagogical practices in engineering education. Her background is in dynamics and controls.

Mr. Yung Lun Wong, AquaSolve Ventures

Dr. Marc Compere, Embry-Riddle Aeronautical Univ., Daytona Beach

Dr. Compere is an Associate Professor in Mechanical Engineering. His background is in dynamic system modeling and simulation, nonlinear control, hardware-in-the-loop, hybrid-electric vehicles, and solar powered water purification. He teaches Instrumentation, Vehicle Dynamics, Hybrid-electric Vehicles, and Senior Design. He recently co-founded a small business called AquaSolve Ventures selling large and small solar powered water purifiers. He is involved in Project Haiti which is a student movement to design the 6th solar water purifier for installation in Haiti this summer. His current research is focused on reducing diesel emissions, improving solar panel effectiveness with phase change materials, and helping to define the water-energy-climate nexus. 


\section{The EPA P3 Program: an Opportunity for Growing Student Entrepreneurs}

Abstract - In this paper we will share our experiences of fostering entrepreneurial spirit through projects funded by EPA (Environmental Protection Agency) P3 (People, Prosperity, and the Planet) Program which hosts the P3 collegiate competition for designing solutions for a sustainable future. Since 2012, we have integrated the P3 competition with the capstone design course of Clean Energy Systems track in mechanical engineering as an effective educational vehicle for introducing the concept of sustainable design. Since the competition focuses on designs which have values of real world application, it is also a great opportunity to create entrepreneurial spirit. We have successfully turned a design from a capstone design prototype to a commercial product through the EPA P3 awards. Similar successful stories have been heard within this program. We will share our story in this paper with an attempt to encourage educators who are working on technologies with commercial viability to take advantage of this unique opportunity to grow more student entrepreneurs.

\section{Introduction}

Finding appropriate projects for capstone design courses has never been an easy task [1, 2]. A good capstone design project should equip students with essential design skills while meeting budget and time constraints of a two-semester course. Because of the small number of senior level students and limited resources and experiences, it is even more challenging for a new and small program like the Mechanical Engineering (ME) program at Embry-Riddle Aeronautical University (ERAU) which was established in Fall 2005. Since its inception, the ME program has adopted the projectbased learning strategy to enhance students' learning experience. All capstone projects are related to collegiate engineering design competitions such as EcoCAR, Formula Hybrid, AUVSI (Association for Unmanned Vehicle Systems Internaltional) student competitions etc. With the steady growth of enrollment, a new Clean Energy Systems (CES) track was created in 2010 to diversify the ME program and increase student competitiveness in the growing energy job market. Inspired by the success of the other two tracks, we searched for a collegiate design competition suitable for the capstone design course of the CES track. The EPA P3 (People, Prosperity, and the Planet) program showed up on the top of the search results.

Aimed at fostering future generations of scientists, engineers, and decision makers to meet sustainability challenges, the EPA launched the P3 Student Design Competition for Sustainability in 2004. The competition has two phases. For the first phase, teams are awarded a $\$ 15 \mathrm{~K}$ (it was $\$ 10 \mathrm{~K}$ from 2004 to 2010) grant to develop their sustainability solution. Then, they present the design in April at the National Sustainability Design Expo in Washington, DC to compete for the P3 Phase II award and a grant of $\$ 75 \mathrm{~K}$ to refine the design, implement it in the field, and bring it to the marketplace. During the past ten years, the EPA P3 program has funded over $\$ 12$ million in grants to more than 500 student teams. These projects mainly address challenges from a wide range of categories including water, energy, agriculture, built environment, materials and chemicals, and clean cookstoves and green infrastructure. Figure 1 illustrates the phases of P3.

We have participated in the EPA P3 competition each year since 2011. In total, we have won four Phase I awards and two Phase II awards with a total amount of $\$ 237,533$. More than 20 
undergraduate and graduate students were involved in these projects. A startup was created out of the project supported by one of the Phase II awards. Although we did not pursue entrepreneurship when we first participated in the P3 competition, we have changed our mindset through the successes and failures of ours and others from the P3 community. With the entrepreneurship oriented mindset, we believe the EPA P3 program has provided us with great opportunities to weave entrepreneurship into engineering education.

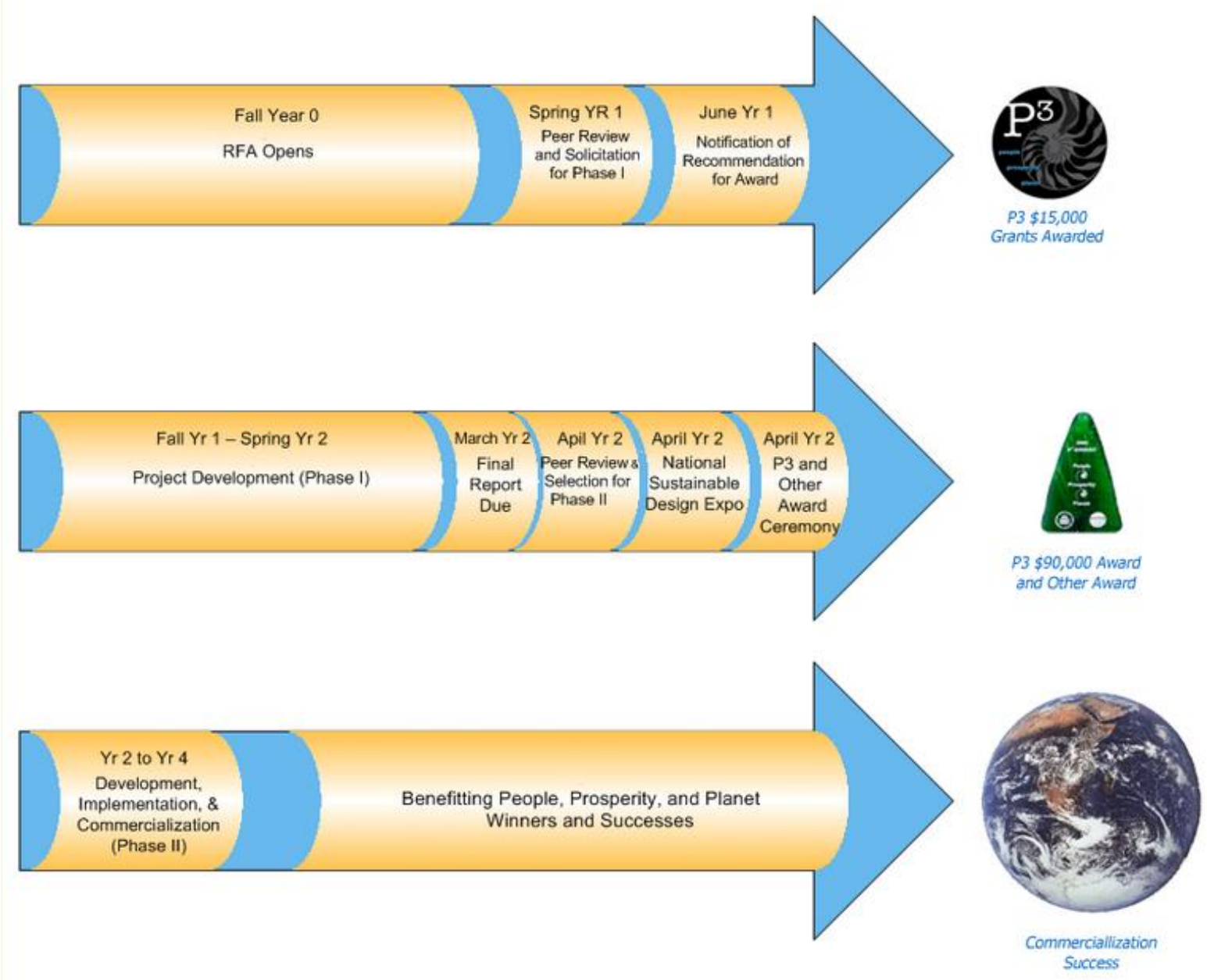

Figure 1 Grant and Award Timeline [3]

In this paper, we will share our stories of using the program to accomplish the educational goals while promoting entrepreneurship among engineering students. We will discuss the lessons we have learned, challenges we are facing, and opportunities we could take as engineering educators through working on the projects supported by the EPA P3 grants.

\section{The Pursuit of Entrepreneurship}

We never thought of promoting entrepreneurship when we first applied for a P3 Phase I grant award because we only had four students in the capstone design course and we thought it would be impossible to complete the design and start a business within a year. So our journey started with a simple goal: design a portable water purification system for disaster relief. 


\section{Capstone Design}

Similar to standard capstone design projects, the Phase I project was intended to achieve the following performance objectives:

1. Application of the design process to a long term project across two semesters.

2. Taking customer goals and converting them into Design Requirements.

3. Developing multiple Conceptual Designs and selecting the best to advance to the next design stage.

4. Developing a Detailed Design and performing parametric studies to refine the selected Conceptual Design.

5. Selecting, ordering, and assembling components that meet the Detailed Design to create a Design Prototype.

6. Testing and refining the Design Prototype into a Final Design with hardware demonstrator.

7. Reporting the Final Design, test results and design conclusions appropriately.

As a course intended to complete the students' engineering education, the course requires that students must demonstrate:

- an ability to apply knowledge of mathematics, science and engineering;

- an ability to design systems, components and processes to meet desired needs;

- an ability to function in multi-disciplinary teams; an ability to identify, formulate and solve engineering problems;

- an understanding of professional and ethical responsibility;

- an ability to communicate effectively an ability to use the techniques, skill and modern engineering tools necessary for engineering practice;

- the ability to understand the impact of engineering solutions in a global and societal context;

- a knowledge of contemporary Clean Energy issues.

The team started the project by defining design requirements and went through the design stages including conceptual design, detailed design, and prototype development. By April 2012, the team completed the prototype design as shown in Figure 2.

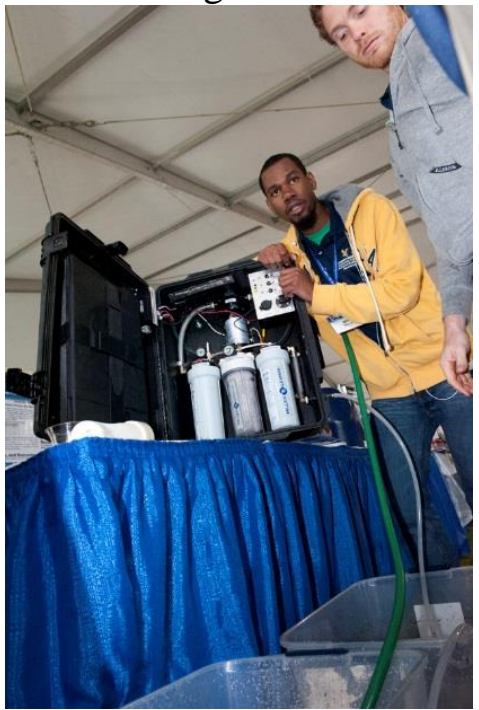

Figure 2 P3 Phase I Prototype Demonstration 


\section{Phase II}

Getting positive feedback and suggestions as well as winning the Phase II grant motivated the team to pursue commercialization of the technology. The team approached the university leadership to share the success. This meeting yielded university support in the form of tuition waivers for a couple of team members' graduate degrees and some additional funds for research and development. Since the university did not have a technology transfer office at the time, the team was referred to the legal department to discuss patenting the technology. A patentability study was completed and the outsourced legal counsel advised that a patent on the technology could be pursued. A provisional patent application on the prototype developed during Phase I was filed protecting the intellectual property (IP) for a year while the team modified and improved the system based on feedback received during the P3 showcase and competition.

Through Phase II, the team made major advances in every area of the technology. This resulted in the first provisional patent to be abandoned and a new one filed. After filing the new provisional patent, the team used some of the funding from the Phase II award to exhibit the system at trade shows in order to get feedback from potential customers. The team researched trade shows whose focus and attendees were tied to the markets the team wanted to target. The people met at these shows gave invaluable advice and some ended up being evaluators of the system.

Parallel to the development of the technology and the IP, the team began working with the local award winning $\mathrm{Z}$ Business Incubation Program. Applying to the incubation program requires taking their Excellence in Entrepreneurship Certificate Course. This 21 hour course trained the team on business basics and helped shape the business model. At the end of the course, each group presented to a panel of judges including investors and incubator staff members. This panel would provide feedback on the business as well as have a hand in accepting or rejecting the team from the program. Luckily, the team was accepted and received all the resources available through the program. From 2012 to 2014, the team was considered a pre-incubation client as the main focus was on proving the technology and improving the product. However, the team did take advantage of the educational seminars and workshops in order to learn about sales, marketing, legal, insurance, and other business topics. The team also learned about another resource called the Small Business Development Center which also offers educational seminars but also offers free personalized business guidance. The team took advantage of this resource as well for help specifically with marketing and branding. At the end of this pre-incubation period, the team cofounded AquaSolve to pursue commercialization of the technology.

\section{Current Status}

In early 2014, the team completed the research and development of the technology, produced an end product (Figure 3) ready for sale, and were preparing for graduation in May. In April, the incubator put together the first annual Innovation Challenge in which six local university teams pitched their business idea to a panel of judges. AquaSolve Ventures won first place which included $\$ 10,000$ prize money and a year free resident enrollment in the incubator. This was the catalyst for the team to work full time on the business. It was after the challenge that AquaSolve and ERAU signed an exclusive license agreement giving exclusive rights to AquaSolve to use the IP. 


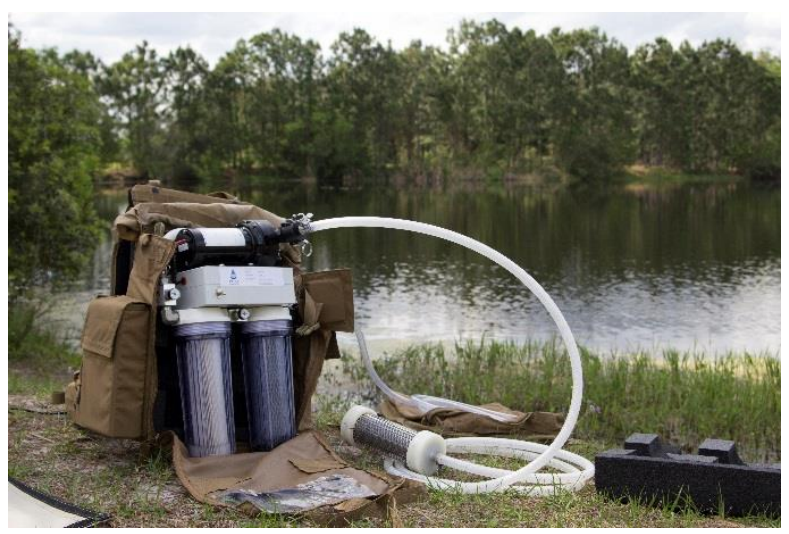

Figure 3 Final Product of Phase II

Since the competition, the co-founders have adopted the lean methodology to create a business model canvas and getting out of the building to validate the model. To do this, the team has gone to multiple trade shows and conferences to network, get feedback, and generate sales. The team has also developed relationships with lawyers, suppliers, shippers, and other people contributing to the success and growth of AquaSolve. Having the ability to say that the product was developed using funds from the EPA and was developed while in school has helped in developing these relationships. Many people have offered their help and suggestions because AquaSolve's vision of helping to solve the global water crisis is a good story and there is potential in the business.

\section{Challenges Faced}

Over the past several years, the principals of AquaSolve have faced many challenges in getting the technology to market. A lot of learning and getting help from mentors and advisors occurred in order to get the team to the point where they are now. The license agreement which the team signed with ERAU was actually the first in the school's history. It was a learning process on both sides. Halfway through the P3 Phase II, the university hired a full time technology transfer and commercialization director who had experience working with student entrepreneurs from another university. Working with this director was easier and more efficient than working with the university's legal department as she understood the tech transfer process and had gone through it with a number of technologies and companies. The documents provided by the university for review and signatures were reviewed by the team's lawyers. However, the team also needed to be aware of the contents of the documents so they had to familiarize themselves with the language of patent applications and license agreements. Having a general knowledge of the language in legal documents also helped in developing the business's legal documents such as the operating agreement, confidentiality agreements, licensing agreements with suppliers, and more.

Once the patent application was filed, licensing agreement was signed, and business was setup, the team used the incubator's resources and mentors to develop strategies in terms of lowering manufacturing cost, product pricing, sales strategies, marketing and branding strategies, scaling strategy and capital raising. These areas are not unique to AquaSolve. As each company develops their business model, each of these areas will need to be thought about and processes developed. Students who have no experience in running their own business or working in industry will struggle with how to run a startup. Having resources to take advantage of whether it is an incubator, accelerator, mentor, or even a friend who's also working in a startup can be very helpful. Being 
able to develop a roadmap will help to focus and prioritize the million things that are on the to-do list. Each business will face periods of hardship but being able to feed off the passion for why you started the business will get you through it.

\section{Discussion}

In the previous sections, we shared how we pursued entrepreneurship through the EPA P3 Phase I and Phase II projects. Entrepreneurship, by the definition we have agreed on, is the pursuit of opportunities beyond resources controlled [4]. We will never have sufficient resources to start and run business, but we could always find opportunities if the ideas have market value. The EPA P3 program invests on design solutions for the sustainability. All teams compete to bring positive impacts on sustainability. The funds provided through the Phase I and Phase II awards would be beneficial for those who already have ideas but need funds to conduct preliminary studies to attract further investment.

From our own experience as a small program in a private engineering oriented institution, we would like to provide the following comments and recommendations.

1. If your program is related to energy, built environment, materials and chemicals, water, agriculture, clean cookstoves, and green infrastructure, the P3 Phase I would be a great funding resource for the capstone design. The Phase I begins in August and the competition is in April, which matches the schedule of standard capstone design courses. By participating the P3 competition, students will be more motivated to work. Their understanding of sustainability and their communication skills will be enhanced by presenting their designs to the audience visiting the competition.

2. If you intend to pursue entrepreneurship during Phase I, a collaboration with faculty from the business school is recommended as engineering faculty may not have the experience and time to train entrepreneurs.

3. It will be more practical to pursue entrepreneurship through Phase II as your ideas have been evaluated by the EPA P3 judge panel and have greater commercialization potentials. Again, it is important to collaborate with faculty with the expertise on entrepreneurship or seek local programs on entrepreneurship.

4. Work closely with the tech transfer office in your institution to make sure the intellectual property is well protected.

5. Continue to attract external funds to complete the commercialization process.

\section{Conclusion}

We have shared our experience of pursuing entrepreneurship through the EPA P3 program. We hope our success opens new horizons to other universities seeking to integrate entrepreneurship into the engineering education. 


\section{References}

[1] Ruocco, A., and Dixon, M., "A multidisciplinary capstone teaching model-an integrated, multilevel, intradisciplinary engineering design approach," Frontiers in Education Conference, 1997. 27th Annual Conference. Teaching and Learning in an Era of Change. Proceedings. Vol. 2, IEEE, 1997, pp. 1011-1014.

[2] Tooley, M.S., and Hall, K.D., "Using a capstone design course to facilitate ABET 2000 program outcomes," Proceedings, ASEE Conference \& Exhibition, 1999,

[3] How to apply P3: People, Prosperity and the Planet Student Design Competition for Sustainability Phase I - Project Development. Retrieved from http://epa.gov/ncer/p3/apply/index.html.

[3] Stevenson, H.H., "New business ventures and the entrepreneur," McGraw-Hill/Irwin, 1998, 